\title{
SEISMIC PERFORMANCE OF CONCRETE GRAVITY DAMS*
}

EIJEST

\author{
Magdy H. Mowafy ${ }^{1}$, Mohamed N. Salem ${ }^{1}$, Tarek N. Salem ${ }^{2}$, Ahmed M. Anwar ${ }^{3}$, Hazem M. El Deeb ${ }^{1 * *}$ \\ ${ }^{1}$ Water Structures Dept., Faculty of Engineering, Zagazig University, Egypt. \\ ${ }^{2}$ Structural Eng. Dept., Faculty of Engineering, Zagazig University, Egypt. \\ ${ }^{3}$ Researcher, Construction Research Institute, National Water Research Center.
}

\begin{abstract}
:
Dams and reservoirs located near populated areas represent a potential risk in the event of uncontrolled release of the reservoir water due to earthquake damage, endangering the people and properties. In the present work, the seismic performance of concrete gravity dams is studied numerically using commercially Finite Element based software ADINA (Automatic Dynamic Incremental Nonlinear Analysis). The study gives deep insight into the procedure of analysis and safety evaluation of concrete gravity dams, as well as improving its stability under earthquake loading. In the present study, the horizontal component of North Ridge earthquake was selected for analysis. The study covers a range of parameters including the effect of earthquake horizontal acceleration component, substrate soil type and strength properties of soil on the stability of concrete gravity dams. The behavior of upstream water surface under seismic shaking was also considered in the research.

The results indicated that the relative uplift force, Ur, is linearly proportion to earthquake intensity. On contrary, Ur, decreases as the relative height of water in the reservoir, $\mathrm{Hw} / \mathrm{H}$, increases. The factors of safety, F.S, against overturning and sliding decrease with increasing the earthquake intensity. It was also found that sliding was the governing factor against failure.
\end{abstract}

Key Words: Numerical analysis; Concrete gravity dam; Finite element; Earthquake.

\section{PERFORMANCE SISMIQUE DES BARRAGES POIDS EN BÉTON}

\section{RÉSUMÉ}

Les barrages et les réservoirs situés à proximité de zones peuplées constituent un risque potentiel en cas de rejet non contrôlé de l'eau du réservoir en raison de dégâts du séisme, mettant en danger les personnes et les biens. Dans le présent travail, la performance sismique des barrages poids en béton est étudiée numériquement en utilisant des éléments finis commercialement logiciel basé ADINA (Automatic Dynamic Incrémental Nonlinear Analysis). L'étude donne un aperçu en profondeur dans la procédure de l'analyse et de l'évaluation de la sécurité des barrages poids en béton, ainsi que l'amélioration de sa stabilité sous charge tremblement de terre. Dans la présente étude, la composante horizontale de North Ridge tremblement de terre a été choisi pour l'analyse. L'étude porte sur une série de paramètres, y compris l'effet du tremblement de terre accélération composante horizontale, type de sol substrat et les propriétés de résistance du sol sur la stabilité des barrage-poids en béton. Le comportement de la surface de l'eau en amont en vertu des secousses sismiques a également été pris en compte dans la recherche.

Les résultats ont montré que la force de soulèvement relatif, Ur, est linéairement proportionnelle à l'intensité tremblement de terre. Le contraire, Ur, diminue à mesure que la hauteur relative de l'eau dans le réservoir, HW / H, augmente. Les facteurs de sécurité, FS, contre le renversement et le glissement diminue avec l'augmentation de l'intensité tremblement de terre. On a également constaté que le glissement a été le facteur déterminant contre l'échec.

MOTS CLES: Analyse numérique; barrage-poids en béton; éléments finis; tremblement de terre.

* Received: 31/10 /2012, Accepted: 11/12 /2012, Ref. No. 128, (Original Paper)

** Contact author (eng_heldeeb@yahoo.com, +2 0 1226644747) 


\section{1- INTRODUCTION}

Dams are structures that are usually designed depending mainly on the engineer experience. The estimation of the exerted dynamic forces due to ground shaking should be of great concern. The difficulty in studying this type of loading that it could not be predicted regarding the incident time, magnitude, and the released destructive energy. In the current paper, numerical investigation has been carried out to highlight the influence of earthquakes on the performance of dams.

Many researches dealt with the failure mechanism of concrete dams subjected to ground shaking [6,7, and 25]. It is however, found that there is a lack of researches exploring the fluid-structure interaction. The effect of different upstream water head on the performance and stability of dams was focused.

Numerical modeling of dams under earthquake loads is a rather difficult process. Many researches adopted numerical models to simulate large dams taking into consideration the nonlinear behavior of such complicated structures $[18,24]$. In addition to simulate the structure and the soil domain, the soil structure interface should be carefully considered to account for the large variations in stresses within this domain. Probably the strongest, most accurate, and most widely used numerical technique is the finite element method. Applying the finite element method along with a reasonable soil model, can give a clear insight into the effect of the studied parameters. Dynamic analysis of soil structure interaction is very complicated. The dynamic loads have different time varying amplitudes, the equation of motion has no simple clear solution, and also the infinite soil domain must be represented for the wave propagation. In addition, the nonlinear soil properties must be taken into consideration for an accurate representation of the model, [19].

In the present work, the seismic performance of dams is numerically studied using ADINA program based on the Finite Element Method [3]. The study is carried out to analyze and assess the safety of concrete gravity dams, and to improve its stability under earthquake type loading.

Thus, the main objectives of this paper include:
1. Studying the effect of earthquake horizontal acceleration component on the seismic performance for concrete gravity dams;

2. Studying the effect of relative height of upstream water surface $\left(\mathrm{H}_{\mathrm{w}} / \mathrm{H}\right)$ on the stability of dams during earthquakes;

3. Studying the effect of soil strength properties on the seismic performance of concrete gravity dams;

4. Studying the factors of safety against sliding and overturning, and induced stresses during earthquake loading, and

5. Studying the uplift water pressure during earthquake and its distribution under the concrete gravity dam.

General layout of the concrete gravity dam overlaying the foundation soil is shown in Fig. (1). The figure shows also the critical zones under consideration during analysis - crest, heel, and toe.

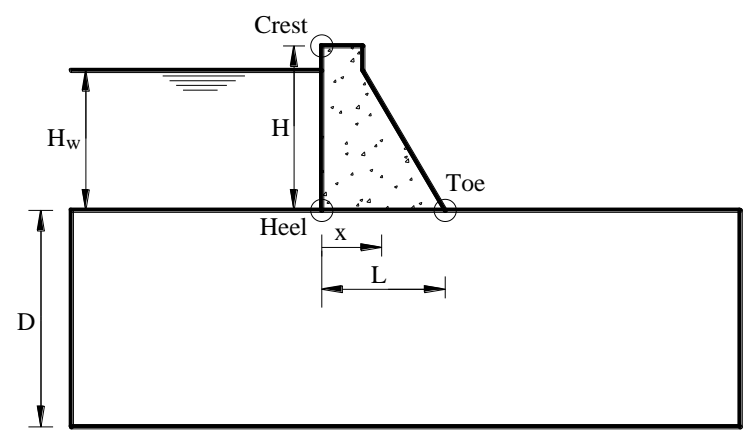
Fig. 1: Problem Definition of Soil Structure
Interaction

\section{2- SOIL MODELING}

The soil is modeled using 4-node plane strain element with 2 displacement degrees of freedom at each node. In addition an extra fluid pressure node is added at each corner node to account for the effect of presence of pore water within the saturated soil media. The overall dimensions extend to a great length in the perpendicular direction, allowing the soil to be modeled as plane strain. It is assumed that just one soil layer of uniform properties exist throughout the mesh.

Mohr-Coulomb Soil Model: The MohrCoulomb soil model is used in Soil Structure 
Interaction (SSI) finite element models efficiently and simply to characterize the nonlinear behavior of the soil under static or dynamic loading conditions. The model is a two parameter model, mainly characterized by the well known soil shear strength parameters (c and $\phi$ ), in addition to other well known soil parameters, like the soil modulus (E), and the Poisson's ratio $(v)$. Soil angle of dilation $(\psi)$ can be fed to the program considering a nonassociated flow rule [3].

It should be noted that some advanced soil models have something like twenty parameters or so. Despite being very accurate when modeling the original problems they were calibrated for, these models usually fail in modeling any other geotechnical problem for simple reasons; first, the large number of model parameters rendered the model much complexity increasing the chance of errors in modeling. In addition, the real meaning of these parameters is not usually comprehended, even for simpler models like the Cam-Clay model [19].

Porous Media Formulation: The porous domain consists of both fluid and solid. The formulation of the porous media is applicable to porous structures subject to static or dynamic loading. It deals with the interaction between the porous solids and pore fluids, which flow through the porous solid skeleton as prospected in Fig. (2). In this study, a 2D plane strain solid element with 4-nodes, and displacement degrees of freedom at each node is used in the analysis. These elements have extra pore pressure nodes at their corner points [3].

Linear Elastic Material Models: The linear isotropic material model is used to model the concrete in this research. When the elasticisotropic and elastic-orthotropic materials are used with the small displacement formulation, the formulation is linear and when used with large displacement analysis, the total or the updated Lagrangian formulation is automatically selected by the program depending on which formulation is numerically more effective [3].

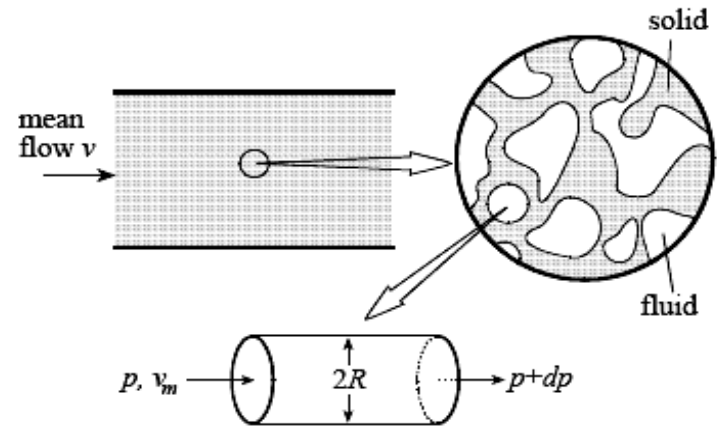

Fig. 2: Illustration of porous media models

In the small displacement formulation, the stress-strain relationship is:

$$
{ }_{0}^{t} \sigma=C_{0}^{t} e
$$

where: ${ }_{0}^{t} \sigma$ : engineering stresses,

$$
{ }_{0}^{t} e \text { : engineering strains. }
$$

While the total Lagrangian formulation, the stress-strain relationship is:

$$
{ }_{0}^{t} S=C_{0}^{t} \varepsilon
$$

In which: ${ }_{0}^{t} S$ : second Piola-Kirchhoff stresses, $t$ ${ }_{0} \varepsilon$ : Green- Lagrange strains.

In the updated Lagrangian formulation, the stress-strain relationship is:

$$
{ }^{t} \tau=C_{t}^{t} \varepsilon^{a}
$$

Where: ${ }^{t} \tau$ : Cauchy stresses, ${ }_{t}^{t} \varepsilon^{a}:$ Almansi strains.

The same matrix $\mathbf{C}$ is employed in all of these formulations. The two material constants used to define the constitutive relation (the matrix C) are $E=$ Young's modulus and $v=$ Poisson's ratio. As long as the strains are small (even with large displacements), the difference in the response predictions obtained with the total and updated Lagrangian formulations is negligible. However, if the strains are large, the difference in the response predictions is very significant and it is recommended that the linear elastic material model not be used.

Soil-Structure Interface: Evaluating the interaction of the soil-structure system subjected to a static load is an important step in any analysis. One of the most important problems in this sort of analysis is the local nonlinear 
behavior of the interface between the soil and the structure foundations. The contact surface approach is used to model soil-structure interface where the nodes of the two surfaces are defined relative to each other by friction coefficient between the surfaces.

The soil type considered in this study was very stiff clay. Soil strength factors were; Young's modulus $=20 \mathrm{MPa}$, Poisson's ratio= 0.45 , Density $=1800 \mathrm{Kg} / \mathrm{m}^{3}$, and Cohesion $=150$ $\mathrm{kPa}$.

Sites with thick deposits of soft and compressible soils have generally been avoided in the past, but as time passes and the better sites are gradually being used, sites with soft foundation must be used with increasing frequency. As a result, the soil properties control the uplift pressure generated under the base of the dam, which affect the safety factors against sliding and overturning. This summoned studying very stiff clay foundation soil type to deduce its effect on the dam stability and safety coefficients.

\section{3- DAM MODELING}

The dam domain is modeled as plane strain. The finite element model, as presented by ADINA software is shown in Fig. (3). The properties of concrete are assigned as follow:

Elastic modulus $(\mathrm{E})=2.1 * 10^{4} \mathrm{MPa}$;

Poisson's ratio $(v)=0.15$;

Density of concrete $(\gamma)=22.0 \mathrm{kN} / \mathrm{m}^{3}$.

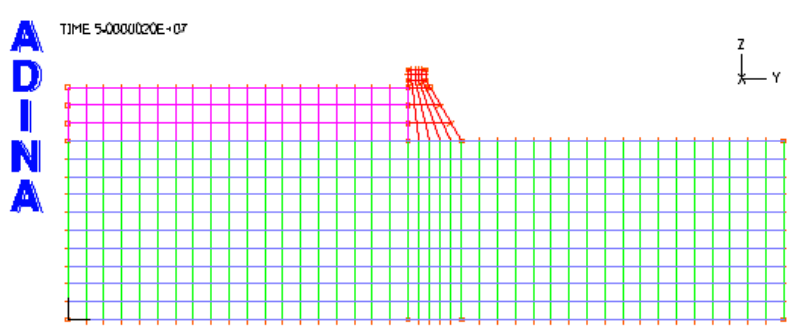

Fig. 3: Finite Element Mesh.

The case studied is a simplified representation of typical concrete gravity dam geometry. The dam section used in the present paper has a base length of $15 \mathrm{~m}$, height of $20 \mathrm{~m}$, crest width of $5 \mathrm{~m}$, foundation soil depth of $50 \mathrm{~m}$, and soil domain extending $200 \mathrm{~m}$ in length.

\section{4- BOUNDARY CONDITIONS}

In this study, the soil was loaded in two stages. Firstly, during the static mode, the boundaries of the model are restrained from movement in the horizontal direction but move freely in the vertical direction. This was done to enable the soil to consolidate under static loads. Secondly, during the dynamic analysis, under earthquake load, the mechanism of repeatable side boundaries is employed in the analysis. Using this approach allowed the energy generated by the ongoing seismic waves to radiate and render the mesh as possible extending to infinity. In such conditions, the displacement and acceleration at the left side degrees of freedom are automatically set equal to those of the right side applying the repeatable side boundaries in the dynamic analysis.

As a real meaning to this approach, the two sides of the mesh boundaries are tied together, therefore, no single side can move alone relative to the other one. This means that the soil media is modeled like a jelly material under applied horizontal earthquake motion. Regarding the horizontal wave propagation, the absence of side supports allowed no end restriction for the incident wave movement. This consequently led the waves to move through the sides without reflecting back into the soil domain.

The domain base movement is restricted in both directions during the static analysis. However, during the dynamic analysis only, the vertical movement is restricted while the horizontal earthquake displacement is applied into the horizontal degree of freedom.

\section{5- ANALYSIS STAGES}

First, the static loading pattern is performed by applying a static load including the soil and dam own weight to perform the static analysis. The second stage in the analysis is the main one in which the dynamic analysis is done. The ground displacement of Northridge horizontal component earthquake [19] was selected as an input. One thousand time steps are performed, with a time step size of 0.02 second, giving a total duration of 20 seconds which is the period of strong shaking of the earthquake used in the analysis (0-20) seconds. The displacement and 
acceleration-time histories of the Northridge earthquake are shown in Figs. (4a) and (4b). During analysis, the same wave form for the earthquake was scaled up and down to fit the desired intensity.

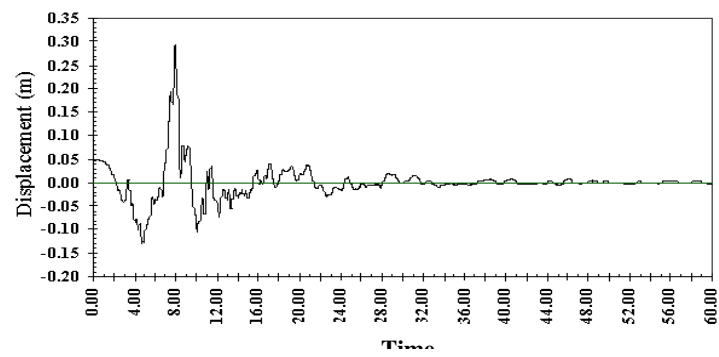

Fig. 4a: Displacement time-history of the Northridge earthquake

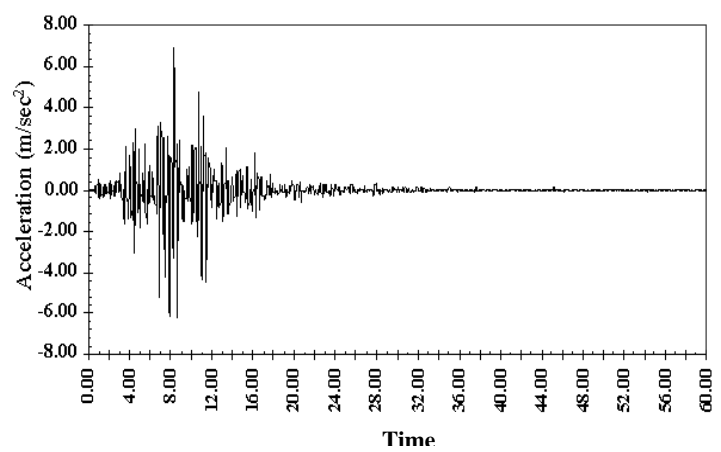

Fig. 4b: Acceleration time-history of the Northridge earthquake

\section{6- PARAMETRS CONSIDERED}

To widen the study range and allow for presenting more practical cases of analysis, a parametric study is performed to study the effect of parameters like the earthquake magnitude and upstream water height. This study will give more insight into the effect of such parameters on the dynamic behavior of dams, and will allow for wider use of the study results into more practical cases.

The Finite Element Program ADINA is used in this study to analyze the stability of concrete gravity dams under seismic loading. Fourty cases were analyzed.

First, the relative height of upstream water surface $\left(\mathrm{H}_{\mathrm{w}} / \mathrm{H}\right)$ was chosen $0.25,0.5,0.75$ and 0.95 . For each case, stationary condition followed by variable earthquake intensities ranges from $0.1 \mathrm{~g}$ to $0.9 \mathrm{~g}$ with an increment of $0.1 \mathrm{~g}$ were applied.
The uplift water pressure and its distribution, factors of safety against sliding and overturning, and stresses among the dam were intensively studied during earthquake loading.

\section{7- ANALYSIS AND DISCUSSIONS}

The effect of relative water height in the reservoir behind the dam and magnitude of earthquake horizontal acceleration component were studied for concrete gravity dams. Results showed the effect of these parameters on the relative uplift pressure, exit gradient, stresses, factors of safety against overturning and sliding, settlement and lateral displacements.

Figs. (5) and (6) show the maximum (at time 7.92 seconds from the beginning of earthquake) settlement and pore pressure distribution contours and color map within the domain for earthquake horizontal acceleration component $0.4 \mathrm{~g}$, showing the maximum and minimum values. The lines indicate a strong concentration at the base and they tend to be circles around the base, whereas they are almost horizontal at a distance from the dam base.

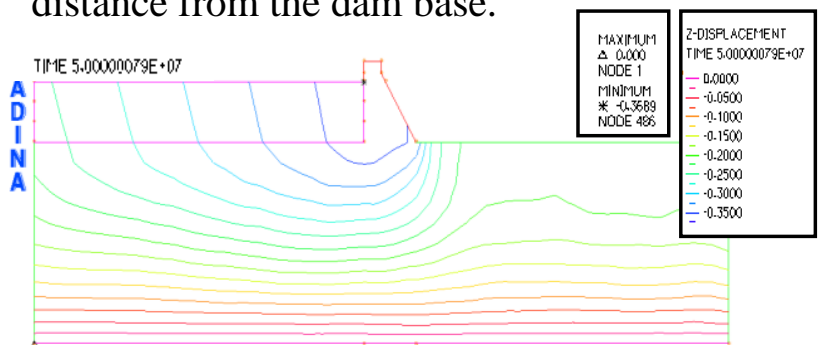

Fig. 5: Settlement distribution, $\mathrm{Hw} / \mathrm{H}=\mathbf{0 . 7 5}$,

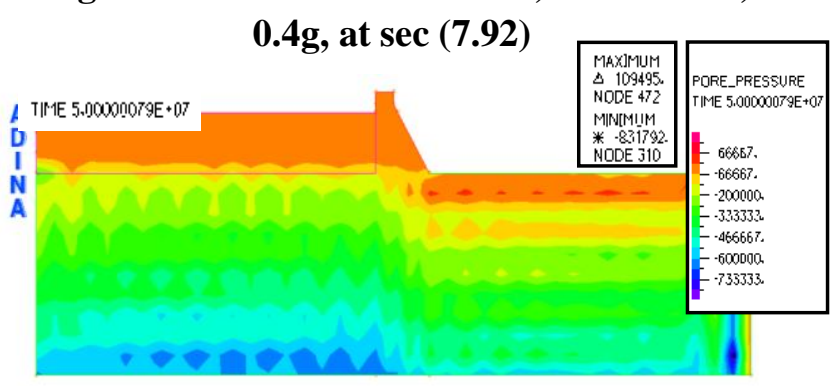

Fig. 6: Pore pressure distribution, $\mathrm{Hw} / \mathrm{H}=0.75$, 0.4g, at sec (7.92)

Fig. (7) shows the stress-time history at the dam heel for earthquake horizontal acceleration component $0.4 \mathrm{~g}$, for the total duration of 20 
Mowafy, Salem, Salem, Anwar, El Deeb

seconds which is the period of strong shaking of the earthquake used in the analysis.

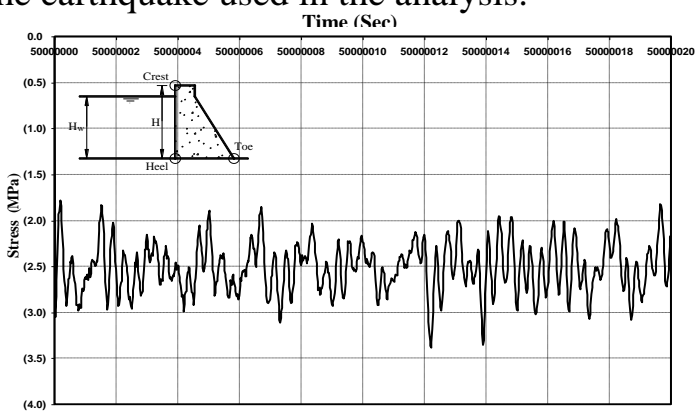

Fig. 7: Stress time history, $\mathrm{Hw} / \mathrm{H}=0.95$, 0.4g. Heel

Figs. (8) and (9) represent the factors of safety, F.S., against overturning and sliding for different earthquake horizontal acceleration components with variation of relative height of water in reservoir, $\mathrm{Hw} / \mathrm{H}$.

The factors of safety were calculated through computing the stability and overturning forces and moments including dam own weight, water pressure, dynamic uplift pressure, and effect of earthquake horizontal acceleration component on vertical and horizontal loads.

It is clear that, the factors of safety, F.S., against overturning and sliding decreases as the earthquake horizontal acceleration component increase. The figures show a large reduction in the safety when for increasing the earthquake magnitude from $0.1 \mathrm{~g}$ to $0.20 \mathrm{~g}$. Larger earthquake magnitudes did not induce such relatively high reduction in the safety factors. Differences between safety factors for earthquake magnitudes of $0.5 \mathrm{~g}$ or higher are small.

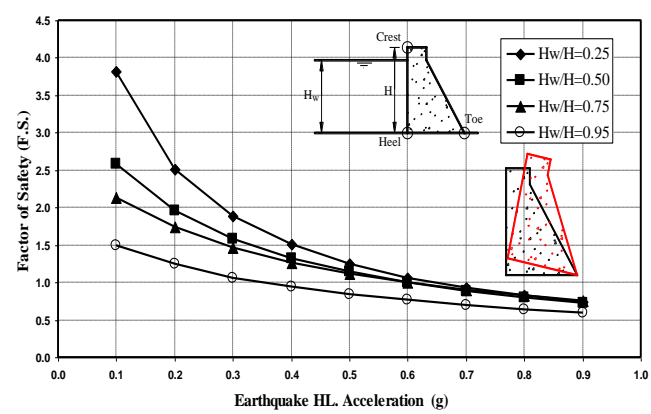

Fig. 8: Factors of safety against overturning

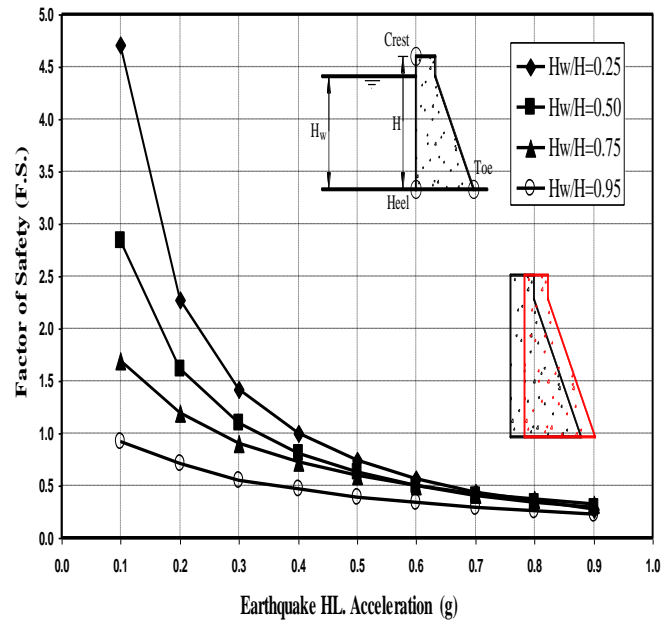

Fig. 9: Factors of safety against sliding

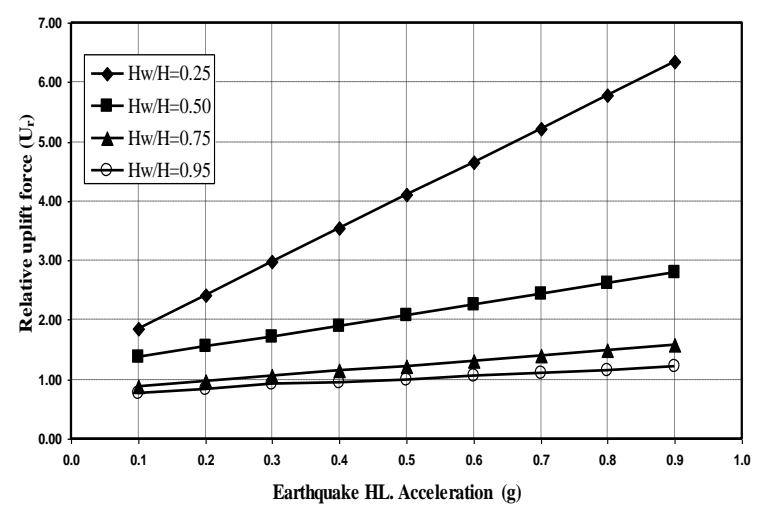

Fig. 10: Relative uplift force for different earthquake intensities.

Fig. (10) describes the relative uplift force, Ur, the ratio between dynamic and static uplift forces, for different earthquake intensities with variation of relative height of water in reservoir, $\mathrm{Hw} / \mathrm{H}$. It is noticed that, the relative uplift force, Ur, has an almost linear relationship with the earthquake horizontal acceleration component. The relative uplift force, Ur, decreases as the relative height of water in reservoir, $\mathrm{Hw} / \mathrm{H}$, increases. It should be noted that the rate of increase in the relative uplift forces with the increase in the earthquake magnitude is much higher for lower water heights in the reservoir. Increasing the relative water height in the reservoir $\mathrm{Hw} / \mathrm{H}$ causes a consistent increase in the static uplift pressure at the dam base. However, this is not the same in the dynamic analysis in which the increase in the dynamic 
uplift pressure is not that much as the static one. Thus, the relative uplift forces, Ur are higher for lower $\mathrm{Hw} / \mathrm{H}$ ratios. Thus, a gradual decrease in the relative uplift pressure is noticed with the gradual increase in the relative water height within the reservoir till converting into negative values of exit gradient, as presented in Figs. (15) and (16) at $\mathrm{Hw} / \mathrm{H}$ of 0.95.

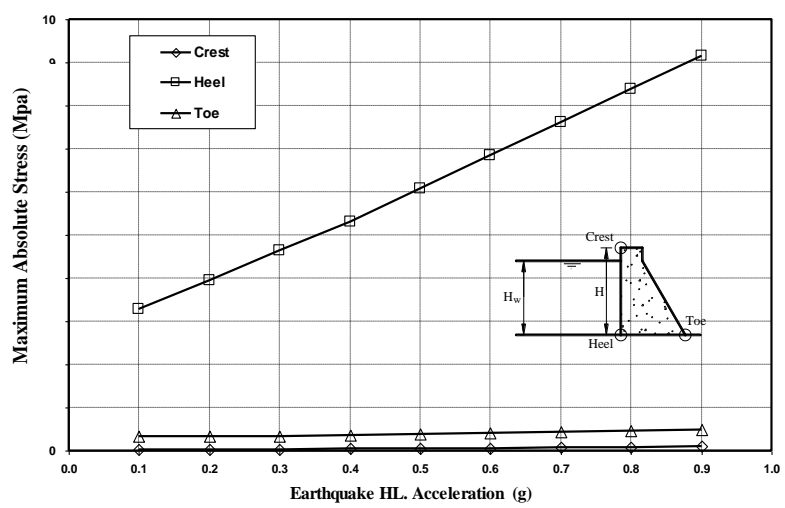

Fig. 11: Maximum stresses for $\mathrm{Hw} / \mathrm{H}=0.25$, for different earthquake intensities

It is noticed from Fig. (11) that the maximum absolute stress occurs mostly at the heel and increases as the earthquake horizontal acceleration component increases. The maximum stress ranges from 3.28 to $9.15 \mathrm{MPa}$ at heel, and from 0.33 to $0.48 \mathrm{MPa}$ at toe.

Figs. (12), (13) and (14) show the settlement and lateral displacement time histories at the crest and heel for earthquake horizontal acceleration component $0.4 \mathrm{~g}$, for the period of strong shaking, 20 seconds.

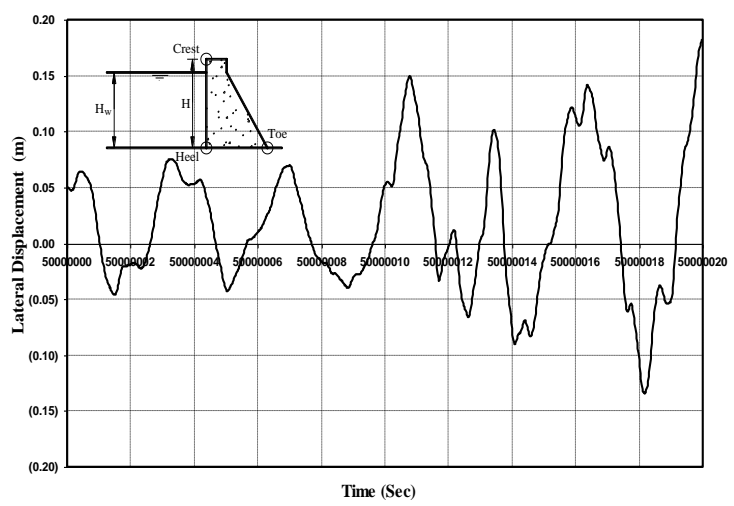

Fig. 12: Lateral displacement time history, $\mathrm{Hw} / \mathrm{H}=0.75$, earthquake horizontal acceleration component $0.4 \mathrm{~g}$, heel.
Fig. (15) shows the relative uplift pressure distribution, $\mathrm{h} / \mathrm{H}_{\mathrm{w}}$, along the dam base, $\mathrm{x} / \mathrm{L}$, for different earthquake horizontal acceleration components, which varies from $0.1 \mathrm{~g}$ to $0.9 \mathrm{~g}$ with an increment of $0.1 \mathrm{~g}$. However, the relative uplift pressure at the toe is gradually reduced with increasing the horizontal earthquake acceleration component.

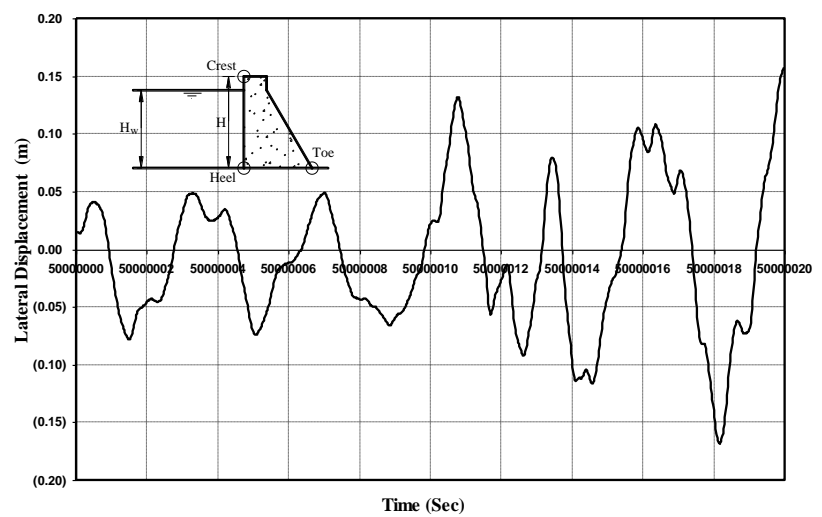

Fig. 13: Lateral displacement time history, $\mathrm{Hw} / \mathrm{H}=0.75$, earthquake horizontal acceleration component $0.4 \mathrm{~g}$, crest.

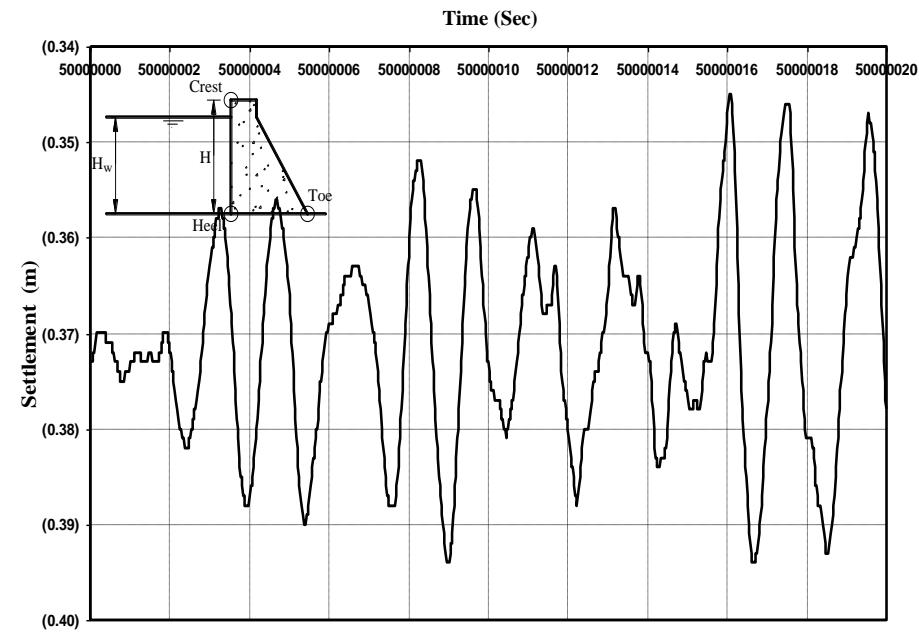

Fig. 14: Settlement time history, $\mathrm{Hw} / \mathrm{H}=0.75$, earthquake horizontal acceleration component $0.4 \mathrm{~g}$, crest

The relative uplift pressure, $h / \mathrm{H}_{\mathrm{w}}$, is equal to 0.77 at the heel and reduced to 0.16 at the toe for earthquake horizontal acceleration components of $0.1 \mathrm{~g}$. The maximum uplift occurs at $x / L=0$. Relative uplift pressure values of 0.81 at the heel and 0.25 at the toe occurred for earthquake horizontal acceleration component, $0.2 \mathrm{~g}$ and the maximum uplift occurs at $\mathrm{x} / \mathrm{L}=0$. Thus, increasing the earthquake acceleration from $0.1 \mathrm{~g}$ to $0.2 \mathrm{~g}$ resulted in an 


\section{SEISMIC PERFORMANCE OF CONCRETE GRAVITY DAMS}

Mowafy, Salem, Salem, Anwar, El Deeb

increase in the relative uplift pressure of 5.2\%. Moreover, increasing the earthquake horizontal component to $0.3 \mathrm{~g}$ up to $0.9 \mathrm{~g}$ with an increment of $0.1 \mathrm{~g}$ resulted in $9.1 \%, 14.3 \%, 19.5 \%, 24.7 \%$, $28.6 \%, 33.8 \%$ and $38.9 \%$ increase over that of $0.1 \mathrm{~g}$.

Fig. (16) represents the exit gradient for different earthquake horizontal acceleration component which varies from $0.1 \mathrm{~g}$ to $0.9 \mathrm{~g}$ with an increment equals $0.1 \mathrm{~g}$. It is noticed that, exit

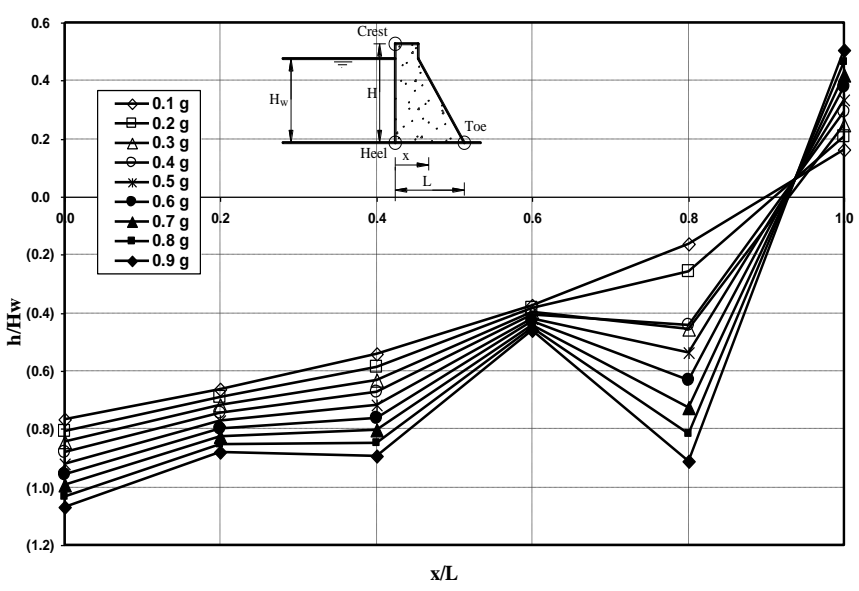

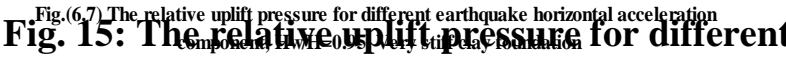
earthquake horizontal acceleration component, Hw/H=0.95.

gradient has an almost linear relationship with the earthquake horizontal acceleration component. It has a negative value thus explaining the dissipation of the uplift pressure at the end of the dam.

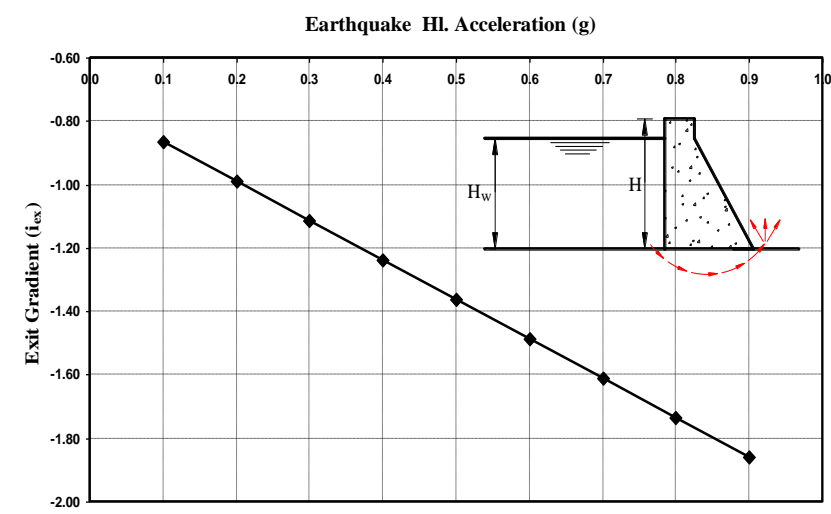

Fig. 16: Exit gradient for different earthquake horizontal acceleration component, $\mathrm{Hw} / \mathrm{H}=\mathbf{0 . 9 5}$

\section{8- CONCLUSIONS}

From the previous analysis of the results, the following conclusions are obtained:
1- In case of concrete gravity dam the relative uplift force, Ur, the ratio between dynamic and static uplift force, increases with an almost linear relationship with the earthquake horizontal acceleration component. Its average value, for very stiff clay foundation and relative height of upstream water level $\mathrm{H}_{\mathrm{w}} / \mathrm{H}=0.25$, was about 1.9 at earthquake horizontal acceleration component, $0.1 \mathrm{~g}$, and it increases by $26.3 \%$, $57.9 \%, 84.2 \%, 115.8 \%, 142.1 \%, 173.7 \%$, $205.3 \%$ and $231.6 \%$ for different earthquake horizontal acceleration component which varies from $0.2 \mathrm{~g}$ to $0.9 \mathrm{~g}$ with an increment equals $0.1 \mathrm{~g}$.

2- The relative uplift force, Ur, decreases as the relative height of water in reservoir, $\mathrm{Hw} / \mathrm{H}$, increases. The relative uplift force, Ur, decreases by about $21.1 \%, 50.0 \%$ and $52.6 \%$ if the relative height of water in reservoir, $\mathrm{Hw} / \mathrm{H}$, increases to $0.50,0.75$ and 0.95 respectively for earthquake horizontal acceleration component, $0.1 \mathrm{~g}$. Higher values of earthquake accelerations did not induce such higher relative uplift forces.

3- The factor of safety, F.S, against overturning decreases with increasing the earthquake horizontal acceleration component. The overturning failure, for concrete gravity dam on very stiff clay foundation started at earthquake horizontal acceleration component of $0.65 \mathrm{~g}$ at $\mathrm{Hw} / \mathrm{H}=0.25$. However, higher water levels of $\mathrm{Hw} / \mathrm{H}=0.95$ causes failures at $0.35 \mathrm{~g}$.

4- The factor of safety, F.S, against sliding also decreases with increasing the earthquake horizontal acceleration component. The sliding failure for concrete gravity dam started at $0.55 \mathrm{~g}$ at $\mathrm{Hw} / \mathrm{H}=0.25$. However, higher water levels of $\mathrm{Hw} / \mathrm{H}=0.95$ causes failures at lower accelerations, as low as $0.22 \mathrm{~g}$. Thus, a sliding failure generally occurs before the overturning failure.

5- The maximum settlement increases with increasing the earthquake horizontal acceleration component and also with relative height of water in reservoir, $\mathrm{Hw} / \mathrm{H}$. A computed settlement of $0.04 \%$ of dam height for earthquake horizontal acceleration component, $0.1 \mathrm{~g}$, and relative height of water in reservoir, $\mathrm{Hw} / \mathrm{H}=0.25$. It increases to $0.16 \%$ of dam height for relative height of water in reservoir, $\mathrm{Hw} / \mathrm{H}$ of 0.95 . 


\section{REFERENCES}

1- Abbas, A.M., and Manohar, C.S., (2002), "Investigations into critical earthquake load models within deterministic and probabilistic frameworks", Earthquake Engineering and Structural Dynamics, Vol. 31, pp. 813-832.

2- Assakkaf, I., (2004), "Design of Concrete Structures", Department of Civil and Environmental Engineering, University of Maryland, College Park.

3- Bathe, K.J., (2011), "ADINA/Standard User's Manual, Version 8.7.3", Watertown, USA.

4- Bhowmik, V.C., and Singh, T.S.K., (2004), "Design of Tuirial Dam", IE Journal, Vol. 85.

5- Bouaanani, N., and Lu, F.Y., (2009), "Assessment of potential-based fluid finite elements for seismic analysis of dam-reservoir systems", Elsevier, Computers and Structures, Vol. 87, pp. 206-224.

6- Calayir, Y., and Karaton, M., (2005), "A continuum damage concrete model for earthquake analysis of concrete gravity damreservoir systems", Elsevier, Soil Dynamics and Earthquake Engineering, Vol. 25, pp. 857-869.

7- Calayir, y., Dumanoglu, A.A., and Bayraktar, A., (1994), "Earthquake analysis of gravity dam-reservoir systems using the Eulerian and Lagrangian approaches", Pergamon, Computers \& Structures, Vol. 59, No. 5, pp. 877-890.

8- Cubrinovski, M., Uzuoka, R., Sugita, H., Tokimatsu, K., Sato, M., Ishihara, K., Tsukamoto, Y., and Kamata, T., (2007), "Prediction of pile response to lateral spreading by 3-D soil water coupled dynamic analysis: Shaking in the direction of ground flow", Elsevier, Soil Dynamics and Earthquake Engineering, Vol. 28, pp. 421-435.

9- Day, R.W., (2002), "Geotechnical Earthquake Engineering Handbook", McGrawHill Companies, ISBN 0-07-137782-4.

10- Field, E.H., Johnson, P.A., Beresnev, I.A., and Zeng, Y., (1997), "Nonlinear ground motion amplification by sediments during the 1994
Northridge earthquake", Journal of Nature, Vol. 390.

11- Gogoi, I., and Maity, D., (2010), "A novel procedure for determination of hydrodynamic pressure along upstream face of dams due to earthquakes", The $14^{\text {th }}$ World Conference on Earthquake Engineering, October 12-17, Beijing, China.

12- Guan, F., and Moore, I.D., (1996), "New techniques for modeling reservoir-dam and foundation-dam interaction", Elsevier, Soil Dynamics and Earthquake Engineering, Vol. 16, pp. 285-293.

13- Hatami, K., (1997), "Effect of reservoir bottom on earthquake response of concrete dams", Elsevier, Soil Dynamics and Earthquake Engineering, Vol. 16, pp. 407-415.

14- Khattab, A.F., (1991), "Design of Dams", Second Edition, Research Institute of Weed Control and Channel Maintenance, Water Research Center, Ministry of Public Works and Water Resources, Cairo, Egypt.

15- Mayoral, J., and Romo, M.P., (2008), "Geo-Seismic environmental aspects affecting tailings dams failures", American Journal of Environmental Sciences, Vol. 4, No. 3, pp. 212222.

16- Miquel, B., and Bouaanani, N., (2010), "Simplified evaluation of the vibration period and seismic response of gravity dam-water systems", Science direct, Engineering Structures, Vol. 32, Issue 8, pp. 2488-2502.

17- Novak, P., Moffat, A.I.B., Nalluri, C., and Narayanan, R., (2007), "Hydraulic Structures", Fourth edition, Taylor \& Francis.

18- Q.S. Li, Z.N. Li, G.Q. Li, J.F. Meng, J. Tang,(2005), "Experimental and numerical seismic investigations of the Three Gorges dam", Elsevier, Engineering Structures 27 (2005) 501-513.

19- Salem, T.N., (1997), "Analysis of Offshore Piles", Unpublished ph.D. Thesis, Department of Structural Design, Zagazig University, Zagazig, Egypt.

20- Sica, S., Magistris, F.S., and Vinale, F., (2002), "Seismic behaviour of geotechnical 
Mowafy, Salem, Salem, Anwar, El Deeb

structures", Annals of Geophysics, Vol. 45, No. 6, December.

21- Valamanesh, V., Estekanchi, H.E., Vafai, A., and Ghaemian, M., (2011), "Application of the endurance time method in seismic analysis of concrete gravity dams", Elsevier, Scientia Iranica, Sharif University of Technology, Vol. 18, Issue 3, pp. 326-337.

22- Wang, X., and Wang, L.B., (2007), "Dynamic analysis of a water-soil-pore water coupling system", Elsevier, Computer and Structures, Vol. 85, pp. 1020-1031.

23- Wieland, M., (2006), "Earthquake safety of existing dams", First European Conference on Earthquake Engineering and Seismology, A joint event of the $13^{\text {th }}$ ECEE \& $30^{\text {th }}$ General assembly of the ESC, 3-8 September, Geneva, Switzerland.

24- Yusuf Calayir, Muhammet Karaton, (2005), "A continuum damage concrete model for earthquake analysis of concrete gravity damreservoir systems", Elsevier, Soil Dynamics and Earthquake Engineering 25 (2005) 857-869.

25- Zhong, H., Lin, G., Li, X., and Li, J., (2011), "Seismic failure modeling of concrete dams considering heterogeneity of concrete", Elsevier, Soil Dynamics and Earthquake Engineering, Vol. 31, Issue 12, pp. 1678-1689. 